\title{
The basic science of optic nerve regeneration
}

\author{
Lindsay Fague, Yin Allison Liu, Nicholas Marsh-Armstrong \\ UC Davis Eye Center, Department of Ophthalmology \& Vision Science, University of California, Davis, Sacramento, CA, USA \\ Contributions: (I) Conception and design: L Fague, N Marsh-Armstrong; (II) Administrative support: None; (III) Provision of study material or \\ patients: None; (IV) Collection and assembly of data: None; (V) Data analysis and interpretation: None; (VI) Manuscript writing: All authors; (VII) \\ Final approval of manuscript: All authors. \\ Correspondence to: Nicholas Marsh-Armstrong. Department of Ophthalmology \& Vision Science, University of California, Davis, 1275 Med Science \\ Drive Rm. 3451, Davis, CA 95616, USA. Email: nmarsharmstrong@ucdavis.edu.
}

\begin{abstract}
Diverse insults to the optic nerve result in partial to total vision loss as the axons of retinal ganglion cells are destroyed. In glaucoma, axons are injured at the optic nerve head; in other optic neuropathies, axons can be damaged along the entire visual pathway. In all cases, as mammals cannot regenerate injured central nervous system cells, once the axons are lost, vision loss is irreversible. However, much has been learned about how retinal ganglion cells respond to axon injuries, and many of these crucial discoveries offer hope for future regenerative therapies. Here we review the current understanding regarding the temporal progression of axonal degeneration. We summarize known survival and regenerative mechanisms in mammals, including specific signaling pathways, key transcription factors, and reprogramming genes. We cover mechanisms intrinsic to retinal ganglion cells as well as their interactions with myeloid and glial cell populations in the retina and optic nerve that affect survival and regeneration. Finally, we highlight some non-mammalian species that are able to regenerate their retinal ganglion cell axons after injury, as understanding these successful regenerative responses may be essential to the rational design of future clinical interventions to regrow the optic nerve. In the end, a combination of many different molecular and cellular interventions will likely be the only way to achieve functional recovery of vision and restore quality of life to millions of patients around the world.
\end{abstract}

Keywords: Retinal ganglion cell; axonal regeneration; optic neuropathy

Submitted Jul 16, 2020. Accepted for publication Jan 15, 2021.

doi: $10.21037 / \mathrm{atm}-20-5351$

View this article at: https://dx.doi.org/10.21037/atm-20-5351

\section{Introduction}

As the sole connection between eye and brain, the axons of retinal ganglion cells (RGCs), which make up the optic nerve, are indispensable for visual function. Unfortunately, unlike many other vertebrates, mammals cannot regenerate damaged axons in their central nervous system (CNS), including those of RGCs, meaning that any damage sustained is irreversible. However, knowledge about axonal destruction and regeneration is fast accumulating, bringing us closer to developing regenerative therapies for CNS tissues. Many other excellent reviews have covered the topic of RGC regeneration (1-5), each from its own perspective. Some discuss the generation and transplantation of new RGCs; others investigate potential pro-regenerative paracrine effects of mesenchymal stem cell replacement therapies $(6,7)$. These topics will not be covered here, and the reader is referred to the other excellent reviews and work cited for an in-depth analysis of these other exciting areas of work. In this review, we will touch on various clinical scenarios in which RGC axonal regeneration therapies might be applied clinically, and then provide a more detailed description of the fundamental principles and pathways involved in the axonal injury as well as the survival and axonal regrowth of RGCs, including both mechanisms intrinsic to the RGCs themselves and extrinsic factors that may be more readily harnessed for translation. 

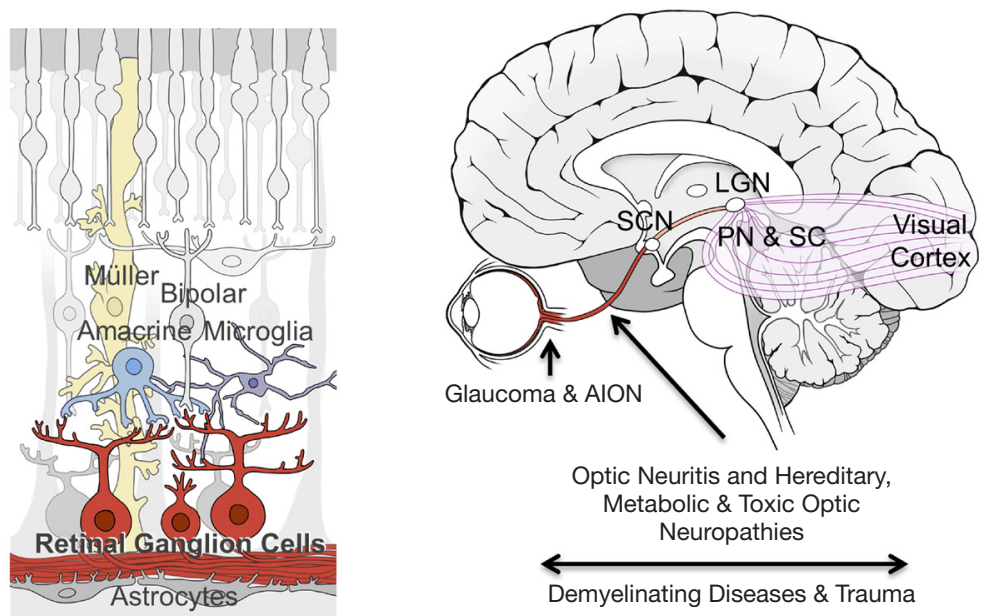

Figure 1 Simple schematics of the retina and human brain emphasizing cells and areas relevant to optic nerve regeneration. Various optic neuropathies affect different parts of the optic nerve; for example, glaucoma and arteritic ischemic optic neuropathy (AION) affect the optic nerve head, while other insults can affect the optic nerve, optic tract and optic radiation. Visual information carried by RGC axons is processed by multiple regions of the brain, in addition to the lateral geniculate nucleus (LGN) that carries most image forming visual information to the visual cortex. Among these other brain nuclei are the superchiasmatic nucleus (SCN), pretectal nuclei (PN) and superior colliculi (SC), which mediate diverse non-image-forming aspects of vision. In the retina, RGCs receive synapses from amacrines and bipolar cells, and are in close contact with glia (Müller cells and astrocytes) as well as microglia.

\section{Common optic neuropathies with injury to retinal ganglion cell axons}

Glaucoma is the most common optic neuropathy resulting from RGC axonal damage and the leading cause of irreversible blindness worldwide, projected to affect over 100 million people by 2040 (8). Glaucoma is frequently, though not always, associated with elevated intraocular pressure, and the optic nerve head is generally believed to be the site of the axonal injury (Figure 1) (9). However, much remains to be learned about changes occurring in the retina and the optic nerve and how they affect progression. Current glaucoma treatment focuses on lowering of intraocular pressure using eye drops or surgical procedures. Even with treatment, however, progression of vision loss still occurs in many patients (10). For this reason, there are ongoing efforts to develop treatments for glaucoma based on neuroprotection, neuroenhancement, and neuroregeneration.

Other optic neuropathies can occur at the optic nerve head but have much shorter time-courses. Ischemic optic neuropathies, either nonarteritic (NAION) or arteritic (AION), involve sudden visual loss, sometimes worsening over days or weeks as the ischemia continues, accompanied by painless edema of the optic disc (11). AION is typically caused by giant cell arteritis and results in severe visual damage, while NAION may stem from small-vessel disease in the nerve and some visual improvement within months is common (11-13).

Other insults affect other parts of the visual pathway. Optic neuritis, acute inflammation of the optic nerve (ON), is characterized by abrupt central vision loss and pain with eye movement. Most commonly associated with multiple sclerosis, patients often recover full vision but can progress to irreversible vision loss $(11,13)$. Interestingly, color vision loss is disproportionately affected in optic neuritis compared to ischemic optic neuropathies, suggesting different RGC populations may be affected in each (11). Traumatic optic neuropathy, while relatively rare, typically occurs following head injuries. It is severe and most often irreversible, similar to the optic nerve crush procedure utilized for laboratory studies (14). Besides head trauma, the ON can sustain acute or progressive physical damage as a result of tumors, compression, and infections $(11,13)$. Increased intracranial pressure can also cause optic neuropathy, for example in pseudotumor cerebri syndrome and space-flight associated neuro-ocular syndrome $(15,16)$. The pathophysiology in the traumatic situations, and quite likely all optic atrophies, is likely to be multifactorial, involving a primary injury followed by a response to this injury which further damages 
other axons $(17,18)$.

Several hereditary disorders also result in ON damage, including the mitochondria related Leber's hereditary optic neuropathy and various genetic dominant optic atrophies $(19,20)$. In addition, other common neurodegenerative diseases such as Alzheimer's disease, Parkinson's disease, and Huntington's Disease all appear to affect RGCs, quite possibly through axonal damage $(21,22)$. While treatments of these conditions ideally address the underlying etiology, in principle all optic neuropathies might benefit from other treatments that promote the regrowth of RGCs axons.

In summary, RGC damage can result from many diseases, occur at various speeds and severities, and may even affect different RGCs subgroups. Unfortunately, once any significant damage to RGC axons has occurred, the RGCs will die, and no treatment currently exist to either halt RGC death or initiate axonal regrowth. Importantly, as we describe below, the clinical window for neuroprotection and regeneration-based interventions is very limited, as the interventions need to act after axonal damage but prior to somal death.

\section{Axonal response to injury: a timeline}

Understanding when to implement an axonal regeneration strategy clinically requires understanding the progression of degeneration after RGC axon injuries. Here we focus mainly on insight gained from the most widely used experimental models, those based on optic nerve crush (ONC) in rodents, though some insight derives from other models, including spinal cord injuries (noted below). ONC involves controlled crushing of the $\mathrm{ON}$ with forceps several millimeters behind the globe, where nearly all axons are myelinated, leaving the $\mathrm{ON}$ sheath and the vasculature supplying the $\mathrm{ON}$ intact (23). Though some degeneration mechanisms are context and injury dependent, as noted elsewhere $(24,25)$, most $\mathrm{ON}$ injury scenarios likely unfold through similar mechanisms to what is outlined here.

\section{Milliseconds to bours after injury}

Immediately following injury in both in-vivo spinal cord and neuronal cell culture models, calcium $\left(\mathrm{Ca}^{2+}\right)$ enters the injury site through voltage-gated calcium channels (26-28). An ex vivo murine spinal cord model also found that $\mathrm{Ca}^{2+}$ is released from the axoplasmic reticulum, possibly contributing to a secondary degenerative signal (29). Removal of this extracellular $\mathrm{Ca}^{2+}$ by a chelator delays axonal degeneration $(27,28)$. $\mathrm{Ca}^{2+}$ influx may be dependent on concurrent $\mathrm{Na}^{+}$entry in some types of injuries, though in a neuroinflammatory model the majority of $\mathrm{Ca}^{2+}$ enters instead through nanoruptures in the plasma membrane $(26,28)$. Importantly, live spinal cord imaging found that a "recoverable period" exists for hours after the initial insult; either $\mathrm{Ca}^{2+}$ clearance or nanorupture resolution protects axons from later swelling and degeneration (30). This increased $\mathrm{Ca}^{2+}$ activates calpains, ubiquitous cysteine proteases, mechanistically linking injury-induced calcium signaling to subsequent axonal degeneration by cytoskeletal degradation (31). Live-imaging of rat $\mathrm{ON}$ shows that within hours of injury, the axons swell and fragment on both sides of the injury (32). In murine spinal cord, the same fragmentation process can be completely blocked by calpain inhibitors (33).

\section{First days after injury}

At this point the proximal (closest to the eye) and distal axonal segments begin distinct degenerative processes. In both CNS and peripheral nervous system (PNS) axons, the distal axon segments fragment through a process called Wallerian degeneration (explained further below), in which the cytoskeleton is degenerated, the axon first forms swellings and then fragments into self-enclosed units, and the myelin disintegrates into elliptical structures $(34,35)$. The proximal axonal segment forms a retraction bulb, elliptical in shape and several times the axonal diameter. This bulb grows progressively larger over weeks as the axonal cytoskeleton depolymerizes and the axon dies back towards the soma $(36,37)$. The retraction bulb is the antithesis of the well-organized growth cones typical of developing or regenerating neurons. In a growth cone, actin structures (lamellipodia and filopodia) at the growing tip are separated from elongating microtubule "beams" by a clearly defined transitional zone (36). In contrast, studies on sciatic nerves found that retraction bulbs feature disorganized, mis-oriented microtubules and no clear separation between microtubule and actin structures (37). Polymerization of both actin and microtubules are critical. Pharmacologic stabilization of microtubules promotes regeneration of CNS spinal cord neurons $(37,38)$. Additionally, combined knockdown in RGCs of two non-muscle myosin II isoforms (motor proteins involved in the movement and restructuring of actin, and normally present in the growth cone transitional zone) promoted marked regeneration persisting for weeks after injury (39). In murine spinal cord following 
injury, some axons attempt regeneration by neurite sprouting, but these sprouts lack directionality, grow only a small distance past the injury site, and ultimately retract (33). Axonal transport of mitochondria also increases in the proximal stump of injured murine intercostal neurons, and this increase in mitochondria axonal localization may be important in neuronal regeneration, as is observed in $C$. elegans motor neuron regeneration $(40,41)$.

Around the first day after injury, the cell's injury response machinery has already been triggered, and studies in sciatic neurons, motor neurons, and RGCs all found that similar molecular injury signals travel from the axonal injury site back to the soma (42-45). Infiltrating neutrophils arrive on the first day post-ONC and are reported to express at least one pro-regenerative factor, oncomodulin $(46,47)$.

\section{The critical first week}

In the first week following ONC the inflammatory response reaches its peak. Infiltrating monocyte-derived macrophages arrive at the optic nerve after the first day $(5,48)$. Of note, immunohistochemical classification of microglia $v s$. macrophages (and thus, their relative contributions) remains difficult, as macrophages take on a microglia-like molecular profile upon infiltration and activation in the CNS (49,50); however, recent retinal single-cell profiling experiments have made huge strides in determining the full complement of different myeloid cells involved in injury responses (51). Astrocytes at the injury site in the $\mathrm{ON}$ degenerate by 3 days and begin to repopulate by day 7 (52). Optic nerve head astrocytes become reactive, losing many fine processes and shrinking in total area covered, but thickening both their soma and primary processes (53). Retinal microglia increase in number, presumably through proliferation (54). The retinal ganglion cell soma receives the signal that it has been damaged within the first week, and many stress responses are subsequently activated $(43,55,56)$. Whether the RGC will die or regenerate is determined in that first week after injury, and this fate depends on various intrinsic and extrinsic factors, described next.

\section{Response of RGCs to axonal damage: intrinsic and extrinsic mechanisms}

Upon receiving the axon injury signal, the cell eventually will either complete a self-destruction program or successfully regenerate its axons. As discussed below, these are related but separable processes. Both intrinsic (internal to the RGC) and extrinsic (mediated by other cell types) factors affect these two decisions, and as such, they will be discussed separately.

\section{Intrinsic pathways}

The fact that RGCs exhibit very different regrowth capacities at different developmental stages demonstrates the importance of intrinsic factors to RGC regeneration. When embryonic or post-natal hamster retinal explants were cultured with either embryonic or post-natal tectal explants, the embryonic retinas showed far greater neurite innervation into the tectal tissues, regardless of the tectal tissue age (57). Similarly, rat RGCs purified prior to birth show markedly greater neurite extension than those harvested after birth. Furthermore, amacrine-conditioned media, but not bipolar conditioned media, converted embryonic retinal explants into a reduced-growth, postnatal-like state, suggesting that biochemical signals from amacrines may cause a postnatal "switch" in RGC regenerative ability (58). A molecular understanding of this innate programming is therefore critical. Interestingly, the innate programming of survival and regeneration appear to be controlled by at least partially distinct pathways, as discussed next.

\section{Intrinsic pathways: survival}

\section{$B A X$ and the intrinsic apoptotic patbway}

Some of the most powerfully neuroprotective measures characterized to date involve the intrinsic apoptotic pathway, which triggers programmed somal death in response to injury or stress signals [reviewed in $(3,59)$ ]. The pathway was discovered when developmental C. elegans screens found several ced (cell death abnormal) genes. Absence of these genes resulted in complete loss of programmed cell death during development (60-62). Mammalian homologs to most ced genes have now been found, including Ced-3/caspase-9, ced-4/Apaf1 and ced-9/Bcl-2 (60,63). Bcl-2 belongs to a large gene family which includes pro-apoptotic genes (e.g., Bax), anti-apoptotic genes (Bcl-2, Bcl-XL) and the BH3only genes (59). Following ER stress or extracellular death signals, $\mathrm{BH} 3$-only proteins interact with Bax and mediate translocation and insertion of Bax into the mitochondrial outer membrane $(59,64,65)$ (Figure 2). Bax-mediated membrane permeabilization triggers the mitochondrion to release pro-apoptotic factors including cytochrome 




Figure 2 Retinal ganglion cell (RGC) death pathways. Both pathways internal to RGCs and factors released from surrounding cell types contribute to the apoptotic cell death of injured RGCs. The signaling protein DLK is produced in injured axons and transported back to the RGC cell soma. There, it activates the intrinsic Jun/JNK signaling pathway, which regulates key genes mediating the cellular injury response. Among these, Jun activates $\mathrm{BH} 3$ proteins, which then interact with the celldeath protein $\mathrm{BAX}$, triggering $\mathrm{BAX}$ translocation to the mitochondrial outer membrane. This results in release of celldeath promoting molecules including cytochrome C, which ultimately activate the caspases. Jun also activates the ER stress signaling molecules, ATFs, which contribute to intrinsic apoptotic cell-death pathways. Meanwhile, external to the cell, high levels of zinc $\left(\mathrm{Zn}^{2+}\right)$ are released from amacrine cells, which synapse onto RGCs, contributing to RGC cell death. Additionally, the extrinsic apoptotic pathway is activated by the release of TNFalpha, FADD, and other cell-death promoting molecules released from nearby Müller glia and microglia. Finally, RGC cellular decay exposes specific membrane components to the external environment, and these components act as an 'eat-me' signal to recruit activated microglia and macrophages, which invade and phagocytose dying cell membranes and organelles.

c, which interacts with Apaf-1 to activate downstream caspases (cysteine protease effectors of cell death) $(64,66)$. In the retina, the balance between Bax and Bcl-2 mediates somal survival after injury. Overexpression of $\mathrm{Bcl}-2$ is neuroprotective both during development and after $\mathrm{ON}$ injury (67). Conversely, Bax is pro-apoptotic, so its absence is protective. Nearly $90 \%$ of RGC somas survive in the Bax knock-out mice up to 18 months following ONC. In these mice, RGC-specific gene markers are downregulated, the cells atrophy, and the surviving cells no longer function electrophysiologically as RGCs (68-70). However, within 4-8 weeks of ONC, Bax knockout mice can still activate an apoptotic response if transfected with Bax, though this ability later disappears as the cells become entirely quiescent (70). These results show that RGC somal death can be slowed, thus offering the possibility of prolonging the therapeutic window for intervention.

\section{DLK/LZK: a critical injury signal}

While several pathways likely alert the soma of cell injury, among the most critical is a mitogen-activated protein kinase (MAPK) signaling cascade (71). MAPK cascades are diverse pathways that convey information to the cell in response to a wide range of extracellular signals (72). One of these cascades, the Jnk (c-Jun N-terminal kinases) cascade, is triggered by dual leucine zipper kinase/leucine zipper kinase (DLK/LZK) signaling in response to axonal injury in murine neurons from both peripheral nervous system (PNS) and CNS $(42,43)$. In both $C$. elegans sensory neurons and murine RGCs, DLK/LZK are retrogradely transported from the axonal site of injury back to the soma, and the cascade (DLK > MAP2Ks > JNKs) ultimately phosphorylates the transcription factor Jun, which regulates key genes mediating the cellular injury response $(43,73)$. DLK also mediates the retrograde transport of other potential injury-signaling molecules, including Stat3 (signal transducers and activators of transcription 3) (42). Importantly, compared to wild type (WT) animals, DLK knockout mice show far fewer gene expression changes post-injury, pointing to the importance of this signaling factor $(43,74)$. Along with Jun, profiling studies have placed DLK/LZK upstream of many transcription factors key to the fate of RGCs, including Klf6, Atf3, and Sox11 $(43,45)$. Also downstream of DLK and the Jnk cascade are the endoplasmic reticulum (ER) stress response genes CHOP (official name: DDIT3) and Atf3 (activating transcription factor 3 ), and the intrinsic apoptotic pathway already described (BH3s > Bax > caspases) (43,75-77). Atf3 is associated with stress responses in both CNS and PNS tissues, and in the PNS, it has been linked to regenerative capacity (77). Atf3 and Atf4 are both upregulated following ON injury of various types $(78,79)$. Functional studies on these genes, however, have yielded nuanced results. While 
a dual Jnk2/3 knockout protects RGCs from somal death in the context of murine $\mathrm{ONC}$, it does not offer similar protection in a mouse glaucoma model $(80,81)$, though complete loss of all Jnks would likely have more pronounced effects $(3,45)$.

There are many reasons why the Jnk pathway may be more important in some types of injury. One reason is that there are other cell death pathways differentially activated by different types of injury. Autophagy, a program by which cells catabolize themselves, for example, can be activated by various insults, and can push towards or away from cell death, depending on the context. Autophagy-related genes (including Atgs and Lc3-II) are upregulated after ONC in mice $(55,82)$. Genetic deletion of Atg5 or Atg 4 increases RGC death, and enhancement of autophagy via rapamycin decreased somal degeneration in a rat optic nerve transection model $(82,83)$. Importantly, though the DLK-initiated Jnk cascade initiates cell death in mammalian RGCs, the same pathway also mediates the proregenerative response seen in both mammalian PNS and in C. elegans $(74,84)$. In both cases DLK also seems to mediate an increase in axonal transport of mitochondria to the injured proximal axonal segment, suggesting that increased metabolic capacity might be important for regeneration $(40,41)$. Since the MAPK pathway is involved in both death and regenerative responses, it is believed to convey an injury "alert" to the soma, rather than directly determining whether a cell dies or regenerates.

\section{Axonal and somal death mechanisms are separable: $W L D s$ and NMAT}

While both somal and axonal loss occur in the same injured neurons, distinct mechanisms control the self-destruction of cell bodies and their still-connected proximal axonal segments versus the distal disconnected side of axons. For example, BAX itself, while highly protective to the RGC soma, is only slightly neuroprotective of the distal axon segments $(3,85)$. Much of the understanding of the axonalspecific degeneration comes from study of a mouse mutant termed Wallerian Degeneration Slow (WLDs), which exhibits a tenfold delay in axon degeneration, accompanied by delayed macrophage recruitment, and delayed clearance of axon and myelin debris. However, WLDs mice display no somal protection after acute injury and variable protection in glaucoma models (35,86-88), demonstrating (like the Bax results) that somal and axonal self-destruction programs are distinct. WLDs is a fusion of the Nmat1 gene with the ubiquitin ligase UBE4B $(89,90)$. All Nmat isoforms catalyze NAD+ synthesis, and overexpression of any Nmat isoform, or other enzymes that make NAD+, delays axonal degeneration (35). Typically, both Nmat2 and NAD+ levels are rapidly depleted following an injury, but WLDs mice exhibit protection from this NAD+ depletion $(91,92)$. As such, the current model holds that the WLDs fusion protein substitutes for the rapidly-lost Nmat2 to confer axonal neuroprotection [reviewed in (35)]. The toll-like receptor adaptor protein Sarm1 (sterile alpha and TIR motif containing 1) has also been linked to Wallerian degeneration, and it degrades NAD+ (93). Activation of Sarm1 promotes axonal degeneration, and deletion protects axons (but not somas) from degeneration after murine ONC (94,95). Interestingly, inhibiting DLK increases axonal Nmat2 and is thus also neuroprotective of axons; in fact, an in-vitro mouse sensory neuronal model found that DLK may contribute to degradation of both Nmat2 and Scg10 (96,97). Scg10 (superior cervical ganglion 10) is a microtubule-binding protein which loses its affinity for tubulin when phosphorylated by Jnk. In vitro models have also linked Scg10 expression to both axonal protection and preservation of mitochondrial transport (98). Taken together, these data suggest that the crosstalk between Nmat2, Sarm1 and the MAP3Ks are key determinants of whether axons degenerate or not, and are thus highly promising targets for neuroprotective strategies, as reviewed in (99). However, since it is still unclear whether WLDs itself affects regeneration (100), it remains to be seen whether any of these genes are good targets for neuroregenerative interventions.

\section{Intrinsic mechanisms: regeneration}

While the axonal injury signal-namely the MAPK (Jnk) cascade initiated by DLK and culminating on the phosphorylation of Jun-initiates the decision between somal death or regeneration, distinct molecular pathways control those processes. Several of the most prominent known regenerative mechanisms are discussed below.

\section{Fak/Stat patbway}

The Janus kinase/signal transducers of transcription (Jak/ Stat) pathway is activated by the binding of extracellular ligands (growth factors, cytokines, and others) and culminates in various Stats binding to specific DNA sequences to alter gene expression (101). Of the four Jak 


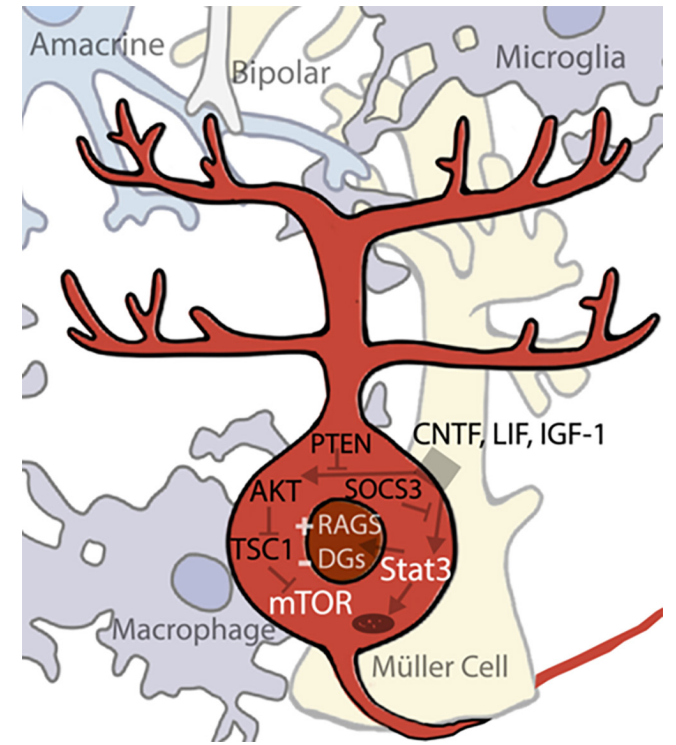

Figure 3 Retinal ganglion cell (RGC) regeneration pathways. Successful axonal regeneration involves both RGC-intrinsic pathways and factors derived from surrounding cell types. Within RGCs, activation of the mTOR and STAT3 pathways both stimulate axonal regrowth. The mTOR pathway is inhibited by AKT, TSC1, and PTEN, and removal of any of those three genes stimulates pathway activation and regeneration. The STAT3 signaling pathway is partly activated by external factors, including the neurotrophins CNTF, LIF, and IGF-1, all secreted from cells near the RGCs (Müller glia, microglia, and monocyte-derived macrophages). Either application of these neurotrophins, removal of SOCS3 (a Stat3 inhibitor), or other methods of activating the Stat 3 signaling pathway induces regeneration. Activated Stat 3 localizes to both nucleus and mitochondria and is known to stimulate downstream gene expression changes in the nucleus. Also intrinsic to RGCs, a de-differentiation event occurs involving downregulation of differentiation genes (DGs) and upregulation of regeneration-associated genes (RAGs), involving diverse transcription factors which reprogram RGCs to a growth-capable state.

and seven Stat genes found in mammals, Stat 3 seems to be particularly critical for regulation of regeneration. AAVmediated expression of Stat 3 in RGCs promotes axonal regeneration (102). The growth factor ciliary neurotropic factor (CNTF), among the most potent pro-regenerative stimuli, works in part by activation of Jak/Stat3. CNTF upregulation coincides with Stat3 upregulation, and direct CNTF application to RGCs in vitro activates the Stat3 pathway (Figure 3) $(103,104)$. A long-established observation that inflammatory stimulation, such as that induced by lens injury, is pro-regenerative (105), was eventually connected to IL-6 family cytokines, CNTF and leukemia inhibitory factor (LIF), both of which signal through Stat3 (1). Conditional deletion of Socs3, a Jak/Stat negative inhibitor, results in an increase in ON regeneration (106). The Kruppel-like signaling factors (Klfs), transcription factors that regulate the regenerative response, also affect Jak/Stat signaling $(107,108)$. However, how activation of Jak/Stat3 affects regeneration is not fully understood; it probably regulates multiple processes. In addition to its own direct modulation of gene expression, Stat3 interacts with c-Jun (downstream of the MAPK (Jnk) cascade initiated by DLK) and potentially other transcription factors as well $(109,110)$. However, there are also some non-nuclear mechanisms through which Stat 3 might also affect regeneration. For example, cytoplasmic Stat3 inhibits autophagy invitro (111), and in both cortical neurons and RGCs it localizes to mitochondria in addition to nuclei, though the significance of this mitochondrial localization is not yet well understood (112). The robustness of the RGC response to CNTF has led to several clinical trials involving CNTFsecreting implants in various retinal diseases. The most promising has been trials involving macular telangiectasia, which have advanced into a current Phase 3 trial; studies of the same implant in glaucoma patients are also ongoing (NCT04577300, NCT02862938).

\section{PI3K/AKT/mTOR}

The other pathway known to be critical for the regulation of regeneration is the mammalian target of rapamycin (mTOR) pathway, a node regulating key cellular processes such as translation and metabolism (113). Upregulation of the mTOR pathway has been found to stimulate regeneration in RGCs, though the results are complex. Activation of PI3K by CNTF/LIF may stimulate the pathway in inflammatory retinal injuries, signaling downstream through AKT onto mTOR (104). IGF-1, another growth factor which signals through $\mathrm{P} 13 \mathrm{~K} / \mathrm{AKT}$, is downregulated after $\mathrm{ONC}$ in rat, and IGF-1 application to the rat retina increases neurite outgrowth (114). Deletion of a negative inhibitor of the mTOR pathway, pten (phosphatase and tensin homolog), stimulates one of the most significant RGC regenerative responses seen to date, and deletion of a second negative inhibitor, TSC1 (tuberous sclerosis 1), is almost as effective $(115,116)$. Similarly, pharmacological inhibition of mTOR by rapamycin inhibits inflammation-induced long-distance 
RGC axonal regeneration in vivo (117). Interestingly, downregulation of mTOR has also been linked to dendrite degeneration and retraction, another physiological effect of RGC injury, and insulin application activates the mTOR pathway to promotes robust dendritic regrowth (118). Several clinical studies have targeted the mTOR pathway by various means. Despite one study which was able to increase plasma IGF-1 levels in patients, a second study did not find any benefit to IGF-1 injection in ALS patients (NCT00871455, NCT00035815). Another currently active study is testing oral administration of the mTOR inhibitor rapamycin, also in ALS patients (NCT03359538).

\section{Reprogramming factors}

A long-standing question regarding regeneration is whether reversion of cells to a fully or partially de-differentiated state is a necessary precursor to regrowth. Two potent transcription factors, c-myc and its target p53, are upregulated in successful PNS regeneration, and promote axonal regeneration when overexpressed in CNS neurons, including RGCs $(119,120)$. As previously mentioned, certain members of the Klf transcription factors are proregenerative, while others, including Klf4, seem to act as transcriptional repressors of RGC axon growth (107). Notably, both c-myc and Klf4 are among the original Yamanaka factors discovered to induce pluripotency by dedifferentiating mouse adult fibroblasts (121). Recently, viralbased induction of OCT4, SOX2, and KLF4 (three of the four Yamanaka factors) has been shown to stimulate axonal regrowth and to promote a "youthful" mRNA profile in the treated eyes (122). Another gene that can broadly induce cellular reprogramming, Lin28, an RNA-binding protein that regulates microRNA processing, is typically expressed in undifferentiated cells and thus seems to be a marker of "stem-ness" $(123,124)$. Lin28 too is upregulated in regenerating PNS neurons after injury, and overexpression of $\operatorname{Lin} 28$ in the murine retina enhances regeneration $(39,125)$, perhaps in an amacrine-dependent manner which enhances RGC responsiveness to IGF (126). The potency of these "reprogramming factors" in inducing regeneration, coupled to RGC down-regulation of many genes and functions associated with a fully differentiated state, suggest that RGC regeneration may require partial dedifferentiation into a more stem-like state. One possibility is that the injury signal conveyed from the axon, mediated by the MAPK (JNK) cascade initiated by DLK, provides such a signal to de-differentiate. Whether that reprogramming leads to death or regeneration, then, might be mediated by the right balance of mTOR and Jak/Stat pathways together with the inhibition of the cell-death pathways.

\section{Combinatorial approaches: successes and challenges}

Unless there is a major conceptual breakthrough, combinatorial approaches will almost certainly be necessary for clinically meaningful regeneration of RGC axons. Indeed, such combination treatments often result in improved regrowth in the mouse ONC model. Some examples include: (I) Conditional deletion of both Socs3 and PTEN enhances regrowth above single deletion of either gene (115); (II) Intraocular application of CNTF yields only limited regeneration, but Socs 3 deletion plus CNTF application strongly increases regrowth (106). (III) Expression of c-myc, viral-mediated CNTF expression, and dual PTEN/Socs3 conditional deletion promotes the most extensive axonal growth seen to date even past the optic chiasm for some axons $(127,128)$-although still a small percentage of all RGCs. (IV) Combined lens injury and PTEN deletion allowed for limited brain re-innervation and even reported partial recovery of visually guided behaviors $(128,129)$. However, sometimes factors improve either survival or regeneration, but inhibit the other-creating a push-pull effect in combinatorial interventions. Some examples of this are as follows. (I) In a conditional PTEN/ DLK dual knockdown model, RGC survival was increased but regrowth was decreased compared to a PTEN knockout alone (43). (II) Lens injury combined with brain-derived neurotrophic factor (BDNF) administration enhanced survival but decreased regeneration compared to a lensinjury paradigm alone (130). Such situations illustrate the need to understand not only the role of individual pathways, but the cross-talk between them as well.

\section{RGC heterogeneity and regeneration}

RGCs exhibit significant heterogeneity, with over 30 subtypes currently recognized in mice. Early morphological characterization of these subtypes was later correlated with distinct physiological signatures and, later, distinct molecular profiles (131-134). Different RGCs display different sizes, respond to either increases or decreases in light or motion, and receive their innervation at different sub-lamina of the inner plexiform layer $(135,136)$. Importantly, RGC subtypes also differentially innervate the brain: in primates most RGCs innervate the image forming pathway (thalamic 
lateral geniculate nucleus, the relay for most information flow to the visual cortex), but other RGCs and, indeed many of the same RGCs, also innervate the superior colliculus, pretectal nucleus, superchiasmatic nucleus (Figure 1). These various brain nuclei and others mediate many non-image forming functions, such as the pupillary reflex and circadian entrainment $(137,138)$, whose disruption severely affect quality of life. Thus, any translational strategy should take into consideration the heterogeneity of RGCs and their effects on vision. Translational strategies should also take into consideration that the targets of RGC axons also likely atrophy and re-wire after the degeneration of RGCs (139).

Recent work has made it clear that RGC subtypes respond differently to both injury and regenerative therapies. Two weeks following ONC, some subtypes survive nearly completely, while others are decimated (140). Regarding regeneration, the mouse alpha-RGCs regenerate more successfully in response to PTEN deletion than other subtypes, in large part because of their responsiveness to osteopontin and IGF (141), but those same cells are preferentially killed by Sox11 overexpression, which promotes regeneration of a different RGC subtype (142). Unfortunately, no individual molecular characteristic seems to confer regenerative capacity, and genes which promote survival in one subtype do not reliably translate to other subtypes (140). Interestingly, different RGC subtypes also respond differently to the effect of visual stimulation on regeneration. Subjecting ONC-lesioned mice daily to a high-contrast visual stimulus for several weeks post-injury increases regeneration of alpha-RGCs. Visual stimulus appears to enhance the effect of mTOR pathway elevation, and strikingly, also results in limited target-specific reinnervation of visual targets in the brain and return of simple visual responses, though not the image-forming functions we typically refer to as "vision" (143).

This differential response of RGCs can be viewed either as positive or negative. Understanding the differential regenerative response of different mouse RGCs may lead to new genes and pathways to affect regeneration. However, it is difficult to understand how to translate mouse studies to humans, since mice do not appear to have clear midget and parasol RGCs, corresponding to the parvo- and magno-cellular visual streams, which constitute the grand majority of RGCs of primates, including humans (144-146). Differential responses of RGCs also make it likely that any simple intervention will have an effect only on some types of RGCs, and may even be deleterious to others. This is yet another reason why we need to understand how some species appear to regenerate all their RGCs (discussed below).

\section{Extrinsic factors}

The intrinsic ability of RGCs to survive insults and regenerate (or not) represents just one piece of the puzzle. Neighboring cells, including astrocytes, Müller glia, microglia, and infiltrating myeloid cells, also play crucial roles. Often, these cells affect both survival and regeneration. Here we discuss these cells separately based on their location and whether those cells affect RGC somas and proximal parts of axons in the retina or their axons in the optic nerve.

\section{Extrinsic factors: retina neurons and glia}

RGCs receive chemical and electrical synaptic inputs from both amacrine and bipolar cells, and recent work suggests that these interactions play a role in the decision as to die or regenerate. For one, amacrine and bipolar input are prime candidates to mediate the light-driven promotion of RGC regeneration (143), though, in principle this effect could be mediated by light-sensing molecules within RGCs (for example, melanopsin or chryptochromes). Another study, however, found that synapses onto RGCs are deleterious. Levels of $\mathrm{Zn}^{2+}$ increase in the inner plexiform layer (where amacrines synapse onto RGCs) within 1 day after injury, and is transferred to RGCs by $2-3$ days, and this $\mathrm{Zn}^{2+}$ elevation negatively affects RGC survival (147). It also remains possible that glutamate excitotoxity contributes to RGC death, though this is no longer considered the central mechanism of cell death as it once was (148). The one major RGC neuroprotective clinical trial to take place (NCT00168350), which did not reach its endpoints, was a study based on this premise that glutamate excitotoxity was the key driver of RGC death. This premise is now considered flawed, highlighting how much our understanding of RGC's response to injury has evolved in recent years.

In addition to these neuronal connections synapsing with RGCs, two major glial populations, Müller glia and astrocytes, enwrap RGCs and their axons and are a critical source of extrinsic signaling regulating both survival and regeneration. Like the intrinsic pathway previously discussed, the extrinsic apoptotic pathway ultimately converges on caspases which dismantle the cell, but is instead activated by extracellular ligands, including the fas- 
associated death domain protein (FADD) and tumor necrosis factor alpha (TNF $\alpha)$ (Figure 2) (66,149). Application of $\mathrm{TNF} \alpha$ results in both oligodendrocyte degeneration and RGC death (150). Interestingly, TNF $\alpha$ is upregulated in human glaucoma patients, and in a rat glaucoma model, and Müller glia and microglia/macrophages secrete TNF $\alpha$ upon ocular hypertensive stress (151). Inhibition of either TNFa directly or via the calcium-permeable AMPAR receptors, which TNF $\alpha$ typically traffics to the membrane, resulted in substantially improved RGC survival (152).

RGCs also express receptors for many neurotrophins, small trophic factors involved in synapse formation, growth, differentiation, and proliferation within the CNS (153). Of these, BDNF is an astrocyte-secreted factor which is neuroprotective of both RGC axons and soma but does not affect axonal regeneration $(130,154)$. Transfection of Müller cells with a BDNF encoding construct induced them to secrete BDNF and protected RGCs (155). Interestingly, transport of BDNF to the soma is impaired in several glaucoma mouse models $(156,157)$. Additionally, the IL-6 family cytokines CNTF and LIF are produced as part of the inflammatory response to injury by retinal astrocytes, activated microglia, and Müller glia cells in various retinal/ axonal injury models. Notably, of all the trophic factors, CNTF/LIF, are the only ones that confer both somal neuroprotection and axonal pro-regeneration effects on RGCs $(103,104,158)$.

\section{Extrinsic factors: optic nerve glia}

Unlike CNS neurons, PNS neurons regrow and form functional synapses after injury; and Schwann cells, the myelinating cells of the PNS, are critical to this regeneration (159). Upon injury, Schwann cells dedifferentiate into a progenitor-like state with repairpromoting characteristics including neurotrophic factor secretion, proliferation, and debris clearance (160). One of the earliest, and to date most effective, ON regeneration experiments was insertion of a peripheral nerve graft into the region of an $\mathrm{ON}$ transection, first done by Ramón y Cajal (161). This crude surgery allows RGCs not only to successfully regrow through the graft, but also to reinnervate central brain targets and even lead to partial restoration of visual function (162-164). While this may somewhat be due to pro-regenerative trophic factors within the graft, it is widely accepted that the CNS environment also actively inhibits regeneration.

In the CNS, it is oligodendrocytes that myelinate axons, and oligodendrocyte-derived myelin blocks regeneration (165). This inhibition is mediated by multiple myelin proteins, including membrane-associated glycoprotein (MAG), Nogo, and oligodendrocyte-myelin glycoprotein (OMgp)—all of which signal through the RGC-expressed NogoR receptor (166-171). While NogoR modulation increases optic nerve regeneration in various paradigms, the results are complex. By itself, viral-mediated NogoR knockdown in the $\mathrm{ON}$ is minimally effective; combined with lens injury, it evokes markedly stronger regeneration, and when all 3 isoforms of NogoR are genetically eliminated, moderate regeneration occurs after ONC even without other interventions $(172,173)$. Recently, however, a clinical trial testing a NogoR antibody in spinal cord injury (SCI) found good tolerability but no functional recovery in para- or tetraplegic patients (174). Despite this, clinical trials using this particular drug are continuing (NCT0393532). Another trial in spinal cord injury patients testing a soluble protein "decoy" or "trap" which sequesters MAG, Nogo, and OMgp is also underway (NCT03989440).

In addition to CNS myelin inhibition, the ON environment itself becomes regeneration-prohibitive following injury through formation of a glial scar. Astrocytes within the ON lose their ramified morphology, become proliferative and phagocytic, and secrete many extracellular matrix proteins that form a unique and disorganized matrix (175). Together with infiltrating non-resident macrophages (discussed next), a buildup of tissue forms which replaces the dying RGC axons within the ON. This glial scar produces various proteins which inhibit RGC regrowth, including ephrins and chondroitinsulfate proteoglycans (CSPGs) $(176,177)$. Degrading these CSPG glycosaminoglycan chains enhances axonal regrowth, at least in a spinal cord injury model (178). However, other data suggest the glial scar may not inhibit CNS regeneration at all. In fact, inhibiting the formation of the glial scar was detrimental to spontaneous regrowth in a mouse SCI model (179).

Both glial-scar signaling and myelin/NogoR-associated inhibition ultimately converge on RhoA (ras-homolog gene A), which binds to its receptor ROCK (Rhoassociated protein kinase) and mediates actin cytoskeleton decay and growth cone collapse $(180,181)$. Since many extrinsic inhibitory factors converge on RhoA/ROCK, several studies, including some clinical trials on a range of neurodegenerative diseases or injuries, have targeted them directly. The results have been mixed. RhoA inhibition resulted in modest axon outgrowth post-injury both in vitro 
and in vivo; the effect was greatly increased when combined with lens injury $(182,183)$. An active study is investigating the potential of the ROCK inhibitor, fasudil, to improve outcomes in amyotrophic lateral sclerosis (ALS) patients (NCT03792490). On the other hand, in late 2018 a clinical trial testing a third Rho inhibitor in spinal cord injury patients was halted due to futility (NCT02669849). Overall, blocking extrinsic inhibitory effects will likely need to be combined with the promotion of intrinsic pro-regenerative states in order to achieve clinically relevant results.

\section{Extrinsic factors: inflammatory cells}

The same C. elegans developmental screens which discovered the intrinsic apoptotic ced pathway genes also discovered several extrinsic ced genes which mediate engulfment of apoptotic cells $(61,184)$. Though $C$. elegans lacks professional (macrophage-like) phagocytes, many extrinsic ced genes expressed by engulfing cells in $C$. elegans have orthologs in mammalian phagocytes (185). Two of these are ced-7/ABCA1 and ced-1/Megf10. Ced-7 is a cholesterol transporter expressed in both dying and engulfing cells, and loss of ced-7 in either cell type completely blocks engulfment (184). ced-1/Megf10 is a receptor expressed by the infiltrating macrophages that arrive to phagocytose cellular debris $(186,187)$. Exposed phosphatidylserine molecules, and other cellular components found on the inside of healthy cells, become externalized onto the surface of apoptotic cells, and act as a phagocytic "eat-me" signals which can then be bound by a variety of proteins including ced-1/Megf10, annexin-5, and Mfge8 $(185,187,188)$. Indeed, there are clinical studies ongoing using labeled annexin-5 to visualize dying RGCs in human eyes, though the broad utility of this method is yet to be determined $(189,190)$.

Microglia, the myeloid cells that reside within CNS tissues including retina and optic nerve, proliferate following injury (52). Microglia are capable of rapid activation in response to many extracellular changes (191). During development and injury, microglia selectively prune synaptic connections, and after injury, activated microglia become phagocytic and clear RGC debris $(192,193)$. There is currently a lack of consensus as to whether microglia are more beneficial versus harmful after injury, and the answer is likely to be context dependent. In one study, microglia were neuroprotective during a prolonged experimentally induced injury but microglial presence following the injury hindered recovery (194). Suppression of microglial activation using minocycline treatment increased RGC survival in both optic nerve transection and glaucoma murine models $(195,196)$. However, another study suggested that microglia are not critical for ON degeneration or regeneration (197). The difference may lie in a very specific balance of cytokines and chemokines secreted by activated microglia under different stimuli, but much more work is needed to determine whether these cells are good targets for proregenerative interventions (5). In fact, different states and stages of activation, varied molecular mediators, and extensive crosstalk between cell types are characteristic of all inflammatory cells; for a comprehensive review of the inflammatory response to injury in the $\mathrm{ON}$, the reader is referred to Andries et al. 2020 (5).

\section{Learning from regenerative species}

Unlike mammals, other vertebrates possess extraordinary natural regenerative abilities. Two of the more common models used in biomedical research, Dario renio (zebrafish) and Xenopus laevis (African clawed frogs), display both compelling similarities and notable differences in their response to axon injury relative to mammals. Given the conservation of retina structure, including all the major cell types in retina and optic nerve, and the high genomic conservation between humans and these species $(84 \%$ and $79 \%$ of known human disease-associated genes have a zebrafish and Xenopus homologues, respectively), attaining clinically-relevant regeneration in human RGCs may depend on our first understanding the successful regenerative programs of these other species $(198,199)$. These species' ability to achieve regeneration is likely a combination of multiple pathways in multiple cells all deployed at the right time, as would be expected for processes maintained through selective pressure.

\section{Time to regrow}

Functional studies assessing regeneration in teleosts and amphibians date back to the mid-twentieth century (200-202). Some dismiss studies of regeneration in these species because their retinas include a ciliary marginal zone of cells which continue to divide and differentiate throughout the animal's lifetime, enabling the eye to grow with age $(203,204)$, and because these species can regenerate all retina cell types after severe injuries from either Muller cells in zebrafish or retinal pigment epithelial cells in Xenopus (205-209), features not present in mammals. These retinal regeneration mechanisms notwithstanding, 
however, most axonal regeneration after $\mathrm{ON}$ injury in both species comes from regeneration of existing RGCs, not by the generation of new cells (210). In fact, in fish and frog, $20-25 \%$ of RGCs do die after axon injury, like their mammalian counterparts; but the remaining RGCs survive and regrow their axons $(210,211)$. Regrowth begins anywhere from days to weeks post-injury and re-innervation of brain targets occurs within weeks to months, depending on the size of the animals (212-216). While there are likely to be differences not translatable to humans, including some genes carried by these species which are absent in humans, exploring these naturally regenerative RGCs could yield enormous insight.

\section{Morphological/anatomical comparison of post-injury response in mammals versus fish and frogs}

In Xenopus, the initial progression of axonal injury occurs as it does in mammals: the distal axonal segment undergoes Wallerian degeneration, the proximal segment forms a retraction bulb which progressively degenerates towards the soma, and full brain de-innervation occurs $(215,217)$. Two weeks following injury, the proximal stump shows near-complete demyelination, advanced degeneration of remaining axons, and major changes to the glial and astrocytic architecture. However, distinct growth cones have re-formed within the demyelinated fibers within weeks following injury, and fully regrown axons are largely remyelinated and have successfully re-innervated their brain targets within months (217).

Interestingly, in both fish and frog, regenerating RGC axons make many pathfinding mistakes (218) and when the regenerating fibers initially reach their general target locations in the brain they do not exhibit precise connection patterns $(219,220)$. The initial retinotopic "map" then undergoes an activity-dependent refinement process which recalls the developmental process of synaptic refinement $(221,222)$. Also, it is important to note that both mammalian and fish neurons can regrow in vitro alongside either fish oligodendrocytes or fish-conditioned media, indicative of a growth-permissive ON environment in these species (223). These findings underscore the importance of tracing the contributions of individual cell types within the optic nerve.

Perhaps most telling are the classic eye rotation experiments by Roger Sperry that formed the basis of the chemo-affinity hypothesis for neuronal connectivity. When the optic nerve of a frog was transected and the eye rotated 180 degrees, full reinnervation and return of visual function was still achieved, but visual field perception was also exactly rotated (218). This demonstrated that individual RGCs are imprinted developmentally to recognize their specific brain target—and that even when disconnected, they "recall" that location and can return to it. Since similar spatial identity exists in mammals, it renders the quest for regenerative axonal therapies even more urgent, as stem-cell derived RGC transplants may not have the innate 'foreknowledge' of their desired innervation target, posing yet another barrier to clinical deployment.

\section{Molecular comparison of post-injury response in mammals versus fish and frogs}

Molecular profiling studies have found regulated pathways after ONC to be largely similar between mammals and pro-regenerative species, but there are also some striking differences. In the ER stress response pathway, Atf 3 is strongly upregulated in fish, frogs, and mice, and ddit3/ CHOP, Atf4, and a putative downstream gene Chac1 are upregulated in frogs and mice $(78,215,224)$. Additionally, c-Jun, upstream of several apoptotic pathways, is highly upregulated in both frogs and mice. However, most other canonical apoptotic players showed no change in frog profiling data (215). Another study revealed that inactivation of CDC42, Rac1, and RhoA by a Wntsignaling mechanism functions early on in zebrafish optic nerve regeneration, suggesting that de-inhibitory signaling may be as critical as activation of growth machinery (225). Many transcription factor families also show major changes after injury. As aforementioned, Sox11a/b (related to the reprogramming transcription factor Sox2) has been studied as a pro-regenerative factor in mice and is markedly increased after injury in both frogs and zebrafish $(215,224)$. Klf6 and Klf7 are upregulated in RGC-specific profiling studies in zebrafish and $X$. laevis $(215,224)$ and in mammalian (mouse/rat) retinal profiling studies $(78,79)$. However, in zebrafish, Sox11a/b knockdown had no effect, and only combined knockdown of Klf6a and Klf7a decreased neurite outgrowth in retinal explants (224). Clearly, functional studies will be required to validate the role of any gene discovered via profiling methods. Work in Xenopus found a specific RNA-binding protein was required for optic nerve regeneration, suggesting that post-transcriptional regulation of specific programs may also be critical (211). More recently, several interesting connections between transcription factor binding sites and chromatin accessibility have been discovered in zebrafish; 
the question of epigenetic mechanisms of regenerative control certainly deserve further exploration (226).

One interesting example of species differences is SOCS3, a Jak/Stat inhibitor which enhances regrowth when inhibited in mammalian systems. In Xenopus and zebrafish, SOCS3 levels increase after injury (215). Additionally, in zebrafish retinal explants knockdown of SOCS3 did not affect neurite outgrowth (224). One study in Xenopus investigated this finding further and found that though SOCS3 mRNA levels were increased in RGCs post-injury, protein levels were increased in axons only. However, both mRNA and protein levels of SOCS2, which degrades SOCS3, were increased in the soma but not in axons-all of which suggests that spatial regulation of various signaling factors (in this case, restriction of SOCS3 by SOCS2 to axons-only post-injury) may be as important for regeneration as the presence or absence of the factors themselves (227).

\section{Future directions}

In his book The Abolition of Man, C.S. Lewis proposed a new Natural Philosophy - one which, "when it explained, it would not explain away. When it spoke of the parts, it would remember the whole" (228). Such has been the intent of this review. The problem of $\mathrm{ON}$ regeneration is multifaceted and complex. Regeneration at its core is a race to regrow axons prior to soma death; and both regrowth and survival involve many cell types exerting multiple effects on the overall outcome. Though every contributing element will need to be understood separately, chances are that multiple of them will need to be addressed together for any intervention to be successful clinically.

Clinically, the narrow window between nerve damage and soma death means that acute and traumatic ON injury, such as traumatic brain injury, would require immediate treatment initiation. Prolonged, asynchronized neurodegenerative processes, such as glaucoma, present a longer clinical window, potentially optimal for chronic pro-regenerative therapies. However, the still-unclear pathophysiology of glaucoma, slow progression and suboptimal means of tracking disease progression, make it a sub-optimal candidate for RGC regeneration clinical trials, which are likely better conducted in acute scenarios. In addition, different types of diseases may end up requiring different types of therapies. Those which strike at the optic nerve head, such as ischemic optic neuropathies and glaucoma, may need additional strategies to deal with a restructured optic nerve head and lamina cribosa or constricted vasculature; and congenital disorders which affect mitochondria may never be successful unless the underlying mitochondrial dysfunction is addressed concurrent to administration of axonal regrowth therapies.

Regenerative experiments habitually report success by distances or numbers of regenerating axons. However, the only clinically meaningful measure is restoration of visual function. By any metric, no experimental treatment in mammals to date has achieved much success. A truly successful intervention will likely require understanding what evolution has deemed necessary for the process, information that can only be gained from studying species with intrinsic regenerative capacity. Such understanding could hold the key to finally creating functionally significant regeneration in mammals. Using these insights to achieve success in optic axonal regeneration will not only enable life-altering improvements for millions of vision-impaired patients, but would also likely lead to treatments for a wide range of other diseases and injuries to the CNS.

\section{Acknowledgments}

Many thanks to Derek Welsbie, Anna LaTorre, Paul Sieving and John Keltner for their useful comments on the manuscript. Many thanks to Maggie Chen for the artwork featured in this manuscript.

Funding: Funding was provided to LF by an NIH T32 Vision Science Training Grant to UC Davis.

\section{Footnote}

Provenance and Peer Review: This article was commissioned by the Guest Editor (Susanna S Park) for the series "Novel Tools and Therapies for Ocular Regeneration" published in Annals of Translational Medicine. The article has undergone external peer review.

Conflicts of Interest: All authors have completed the ICMJE uniform disclosure form (available at https://dx.doi. org/10.21037/atm-20-5351). The series "Novel Tools and Therapies for Ocular Regeneration" was commissioned by the editorial office without any funding or sponsorship. The authors have no other conflicts of interest to declare.

Ethical Statement: the authors are accountable for all aspects of the work in ensuring that questions related to the accuracy or integrity of any part of the work are appropriately investigated and resolved. 
Open Access Statement: This is an Open Access article distributed in accordance with the Creative Commons Attribution-NonCommercial-NoDerivs 4.0 International License (CC BY-NC-ND 4.0), which permits the noncommercial replication and distribution of the article with the strict proviso that no changes or edits are made and the original work is properly cited (including links to both the formal publication through the relevant DOI and the license). See: https://creativecommons.org/licenses/by-nc-nd/4.0/.

\section{References}

1. Fischer D, Leibinger M. Promoting optic nerve regeneration. Prog Retin Eye Res 2012;31:688-701.

2. Benowitz LI, He Z, Goldberg JL. Reaching the brain: Advances in optic nerve regeneration. Exp Neurol 2017;287:365-73.

3. Syc-Mazurek SB, Libby RT. Axon injury signaling and compartmentalized injury response in glaucoma. Prog Retin Eye Res 2019;73:100769.

4. Laha B, Stafford BK, Huberman AD. Regenerating optic pathways from the eye to the brain. Science 2017;356:1031-4.

5. Andries L, De Groef L, Moons L. Neuroinflammation and Optic Nerve Regeneration: Where Do We Stand in Elucidating Underlying Cellular and Molecular Players? Curr Eye Res 2020;45:397-409.

6. Lucas-Ruiz F, Galindo-Romero C, García-Bernal D, et al. Mesenchymal stromal cell therapy for damaged retinal ganglion cells, is gold all that glitters? Neural Regen Res 2019;14:1851-7.

7. Osborne A, Sanderson J, Martin KR. Neuroprotective Effects of Human Mesenchymal Stem Cells and PlateletDerived Growth Factor on Human Retinal Ganglion Cells. Stem Cells 2018;36:65-78.

8. Tham YC, Li X, Wong TY, et al. Global prevalence of glaucoma and projections of glaucoma burden through 2040: a systematic review and meta-analysis. Ophthalmology 2014;121:2081-90.

9. Nickells RW, Howell GR, Soto I, et al. Under pressure: cellular and molecular responses during glaucoma, a common neurodegeneration with axonopathy. Annu Rev Neurosci 2012;35:153-79.

10. Weinreb RN, Aung T, Medeiros FA. The pathophysiology and treatment of glaucoma: a review. JAMA 2014;311:1901-11.

11. Ghaffarieh A, Levin LA. Optic nerve disease and axon pathophysiology. Int Rev Neurobiol 2012;105:1-17.
12. Biousse V, Newman NJ. Ischemic Optic Neuropathies. N Engl J Med 2015;373:1677.

13. Behbehani R. Clinical approach to optic neuropathies. Clin Ophthalmol 2007;1:233-46.

14. Martinez-Perez R, Albonette-Felicio T, Hardesty DA, et al. Outcome of the surgical decompression for traumatic optic neuropathy: a systematic review and meta-analysis. Neurosurg Rev 2021;44:633-41.

15. Degnan AJ, Levy LM. Pseudotumor cerebri: brief review of clinical syndrome and imaging findings. AJNR Am J Neuroradiol 2011;32:1986-93.

16. Lee AG, Mader TH, Gibson CR, et al. Space flightassociated neuro-ocular syndrome (SANS). Eye (Lond) 2018;32:1164-7.

17. Yoles E, Schwartz M. Degeneration of spared axons following partial white matter lesion: implications for optic nerve neuropathies. Exp Neurol 1998;153:1-7.

18. Levkovitch-Verbin H, Quigley HA, Martin KR, et al. A model to study differences between primary and secondary degeneration of retinal ganglion cells in rats by partial optic nerve transection. Invest Ophthalmol Vis Sci 2003;44:3388-93.

19. Carelli V, La Morgia C, Valentino ML, et al. Retinal ganglion cell neurodegeneration in mitochondrial inherited disorders. Biochim Biophys Acta 2009;1787:518-28.

20. Lenaers G, Hamel C, Delettre C, et al. Dominant optic atrophy. Orphanet J Rare Dis 2012;7:46.

21. Kersten HM, Danesh-Meyer HV, Kilfoyle DH, et al. Optical coherence tomography findings in Huntington's disease: a potential biomarker of disease progression. J Neurol 2015;262:2457-65.

22. La Morgia C, Di Vito L, Carelli V, et al. Patterns of Retinal Ganglion Cell Damage in Neurodegenerative Disorders: Parvocellular vs Magnocellular Degeneration in Optical Coherence Tomography Studies. Front Neurol 2017;8:710.

23. Li Y, Schlamp CL, Nickells RW. Experimental induction of retinal ganglion cell death in adult mice. Invest Ophthalmol Vis Sci 1999;40:1004-8.

24. Berkelaar M, Clarke DB, Wang YC, et al. Axotomy results in delayed death and apoptosis of retinal ganglion cells in adult rats. J Neurosci 1994;14:4368-74.

25. Villegas-Pérez MP, Vidal-Sanz M, Rasminsky M, et al. Rapid and protracted phases of retinal ganglion cell loss follow axotomy in the optic nerve of adult rats. J Neurobiol 1993;24:23-36.

26. Wolf JA, Stys PK, Lusardi T, et al. Traumatic axonal injury 
induces calcium influx modulated by tetrodotoxin-sensitive sodium channels. J Neurosci 2001;21:1923-30.

27. George EB, Glass JD, Griffin JW. Axotomy-induced axonal degeneration is mediated by calcium influx through ion-specific channels. J Neurosci 1995;15:6445-52.

28. Witte ME, Schumacher AM, Mahler CF, et al. Calcium Influx through Plasma-Membrane Nanoruptures Drives Axon Degeneration in a Model of Multiple Sclerosis. Neuron 2019;101:615-24.e5.

29. Stirling DP, Cummins K, Wayne Chen SR, et al. Axoplasmic reticulum $\mathrm{Ca}(2+)$ release causes secondary degeneration of spinal axons. Ann Neurol 2014;75:220-9.

30. Williams PR, Marincu BN, Sorbara CD, et al. A recoverable state of axon injury persists for hours after spinal cord contusion in vivo. Nat Commun 2014;5:5683.

31. Goll DE, Thompson VF, Li H, et al. The calpain system. Physiol Rev 2003;83:731-801.

32. Knöferle J, Koch JC, Ostendorf T, et al. Mechanisms of acute axonal degeneration in the optic nerve in vivo. Proc Natl Acad Sci U S A 2010;107:6064-9.

33. Kerschensteiner M, Schwab ME, Lichtman JW, et al. In vivo imaging of axonal degeneration and regeneration in the injured spinal cord. Nat Med 2005;11:572-7.

34. Beirowski B, Nógrádi A, Babetto E, et al. Mechanisms of axonal spheroid formation in central nervous system Wallerian degeneration. J Neuropathol Exp Neurol 2010;69:455-72.

35. Conforti L, Gilley J, Coleman MP. Wallerian degeneration: an emerging axon death pathway linking injury and disease. Nat Rev Neurosci 2014;15:394-409.

36. Blanquie $\mathrm{O}$, Bradke F. Cytoskeleton dynamics in axon regeneration. Curr Opin Neurobiol 2018;51:60-9.

37. Ertürk A, Hellal F, Enes J, et al. Disorganized microtubules underlie the formation of retraction bulbs and the failure of axonal regeneration. J Neurosci 2007;27:9169-80.

38. Ruschel J, Hellal F, Flynn KC, et al. Axonal regeneration. Systemic administration of epothilone B promotes axon regeneration after spinal cord injury. Science 2015;348:347-52.

39. Wang XW, Yang SG, Zhang C, et al. Knocking Out Nonmuscle Myosin II in Retinal Ganglion Cells Promotes Long-Distance Optic Nerve Regeneration. Cell Rep 2020;31:107537.

40. Misgeld T, Kerschensteiner M, Bareyre FM, et al. Imaging axonal transport of mitochondria in vivo. Nat Methods 2007;4:559-61.

41. Han SM, Baig HS, Hammarlund M. Mitochondria Localize to Injured Axons to Support Regeneration.
Neuron 2016;92:1308-23.

42. Shin JE, Cho Y, Beirowski B, et al. Dual leucine zipper kinase is required for retrograde injury signaling and axonal regeneration. Neuron 2012;74:1015-22.

43. Watkins TA, Wang B, Huntwork-Rodriguez S, et al. DLK initiates a transcriptional program that couples apoptotic and regenerative responses to axonal injury. Proc Natl Acad Sci U S A 2013;110:4039-44.

44. Welsbie DS, Yang Z, Ge Y, et al. Functional genomic screening identifies dual leucine zipper kinase as a key mediator of retinal ganglion cell death. Proc Natl Acad Sci U S A 2013;110:4045-50.

45. Welsbie DS, Mitchell KL, Jaskula-Ranga V, et al. Enhanced Functional Genomic Screening Identifies Novel Mediators of Dual Leucine Zipper Kinase-Dependent Injury Signaling in Neurons. Neuron 2017;94:1142-54.e6.

46. Yin Y, Cui Q, Gilbert HY, et al. Oncomodulin links inflammation to optic nerve regeneration. Proc Natl Acad Sci U S A 2009;106:19587-92.

47. Kurimoto T, Yin Y, Habboub G, et al. Neutrophils express oncomodulin and promote optic nerve regeneration. J Neurosci 2013;33:14816-24.

48. Yin Y, Henzl MT, Lorber B, et al. Oncomodulin is a macrophage-derived signal for axon regeneration in retinal ganglion cells. Nat Neurosci 2006;9:843-52.

49. Shechter R, London A, Varol C, et al. Infiltrating bloodderived macrophages are vital cells playing an antiinflammatory role in recovery from spinal cord injury in mice. PLoS Med 2009;6:e1000113.

50. O'Koren EG, Mathew R, Saban DR. Fate mapping reveals that microglia and recruited monocyte-derived macrophages are definitively distinguishable by phenotype in the retina. Sci Rep 2016;6:20636.

51. Ronning KE, Karlen SJ, Miller EB, et al. Molecular profiling of resident and infiltrating mononuclear phagocytes during rapid adult retinal degeneration using single-cell RNA sequencing. Sci Rep 2019;9:4858.

52. Qu J, Jakobs TC. The Time Course of Gene Expression during Reactive Gliosis in the Optic Nerve. PLoS One 2013;8:e67094.

53. Sun D, Lye-Barthel M, Masland RH, et al. Structural remodeling of fibrous astrocytes after axonal injury. J Neurosci 2010;30:14008-19.

54. Wohl SG, Schmeer CW, Witte OW, et al. Proliferative response of microglia and macrophages in the adult mouse eye after optic nerve lesion. Invest Ophthalmol Vis Sci 2010;51:2686-96.

55. Kim SH, Munemasa Y, Kwong JM, et al. Activation 
of autophagy in retinal ganglion cells. J Neurosci Res 2008;86:2943-51.

56. Hu Y, Park KK, Yang L, et al. Differential effects of unfolded protein response pathways on axon injuryinduced death of retinal ganglion cells. Neuron 2012;73:445-52.

57. Chen DF, Jhaveri S, Schneider GE. Intrinsic changes in developing retinal neurons result in regenerative failure of their axons. Proc Natl Acad Sci U S A 1995;92:7287-91.

58. Goldberg JL, Klassen MP, Hua Y, et al. Amacrine-signaled loss of intrinsic axon growth ability by retinal ganglion cells. Science 2002;296:1860-4.

59. Maes ME, Schlamp CL, Nickells RW. BAX to basics: How the BCL2 gene family controls the death of retinal ganglion cells. Prog Retin Eye Res 2017;57:1-25.

60. Chinnaiyan AM, O'Rourke K, Lane BR, et al. Interaction of CED-4 with CED-3 and CED-9: a molecular framework for cell death. Science 1997;275:1122-6.

61. Ellis HM, Horvitz HR. Genetic control of programmed cell death in the nematode C. elegans. Cell 1986;44:817-29.

62. Conradt B, Wu YC, Xue D. Programmed Cell Death During Caenorhabditis elegans Development. Genetics 2016;203:1533-62.

63. Zou H, Henzel WJ, Liu X, et al. Apaf-1, a human protein homologous to C. elegans CED-4, participates in cytochrome c-dependent activation of caspase-3. Cell 1997;90:405-13.

64. Desagher S, Osen-Sand A, Nichols A, et al. Bidinduced conformational change of Bax is responsible for mitochondrial cytochrome $\mathrm{c}$ release during apoptosis. J Cell Biol 1999;144:891-901.

65. Nechushtan A, Smith CL, Hsu YT, et al. Conformation of the Bax C-terminus regulates subcellular location and cell death. EMBO J 1999;18:2330-41.

66. Lowe SW, Cepero E, Evan G. Intrinsic tumour suppression. Nature 2004;432:307-15.

67. Bonfanti L, Strettoi E, Chierzi S, et al. Protection of retinal ganglion cells from natural and axotomy-induced cell death in neonatal transgenic mice overexpressing bcl2. J Neurosci 1996;16:4186-94.

68. Semaan SJ, Li Y, Nickells RW. A single nucleotide polymorphism in the Bax gene promoter affects transcription and influences retinal ganglion cell death. ASN Neuro 2010;2:e00032.

69. Janssen KT, Mac Nair CE, Dietz JA, et al. Nuclear atrophy of retinal ganglion cells precedes the bax-dependent stage of apoptosis. Invest Ophthalmol Vis Sci 2013;54:1805-15.

70. Donahue RJ, Maes ME, Grosser JA, et al. BAX-Depleted
Retinal Ganglion Cells Survive and Become Quiescent Following Optic Nerve Damage. Mol Neurobiol 2020;57:1070-84.

71. Rishal I, Fainzilber M. Axon-soma communication in neuronal injury. Nat Rev Neurosci 2014;15:32-42.

72. Keshet $Y$, Seger R. The MAP kinase signaling cascades: a system of hundreds of components regulates a diverse array of physiological functions. Methods Mol Biol 2010;661:3-38.

73. Holland SM, Collura KM, Ketschek A, et al. Palmitoylation controls DLK localization, interactions and activity to ensure effective axonal injury signaling. Proc Natl Acad Sci U S A 2016;113:763-8.

74. Shin JE, Ha H, Kim YK, et al. DLK regulates a distinctive transcriptional regeneration program after peripheral nerve injury. Neurobiol Dis 2019;127:178-92.

75. Hunt D, Hossain-Ibrahim K, Mason MR, et al. ATF3 upregulation in glia during Wallerian degeneration: differential expression in peripheral nerves and CNS white matter. BMC Neurosci 2004;5:9.

76. Lindwall C, Kanje M. Retrograde axonal transport of JNK signaling molecules influence injury induced nuclear changes in p-c-Jun and ATF3 in adult rat sensory neurons. Mol Cell Neurosci 2005;29:269-82.

77. Hunt D, Raivich G, Anderson PN. Activating transcription factor 3 and the nervous system. Front Mol Neurosci 2012;5:7.

78. Yasuda M, Tanaka Y, Ryu M, et al. RNA sequence reveals mouse retinal transcriptome changes early after axonal injury. PLoS One 2014;9:e93258.

79. Yasuda M, Tanaka Y, Omodaka K, et al. Transcriptome profiling of the rat retina after optic nerve transection. Sci Rep 2016;6:28736.

80. Fernandes KA, Harder JM, Fornarola LB, et al. JNK2 and JNK3 are major regulators of axonal injury-induced retinal ganglion cell death. Neurobiol Dis 2012;46:393-401.

81. Harder JM, Williams PA, Soto I, et al. Jnk2 deficiency increases the rate of glaucomatous neurodegeneration in ocular hypertensive DBA/2J mice. Cell Death Dis 2018;9:705.

82. Rodríguez-Muela N, Germain F, Mariño G, et al. Autophagy promotes survival of retinal ganglion cells after optic nerve axotomy in mice. Cell Death Differ 2012;19:162-9.

83. Boya P, Esteban-Martínez L, Serrano-Puebla A, et al. Autophagy in the eye: Development, degeneration, and aging. Prog Retin Eye Res 2016;55:206-45.

84. Hammarlund M, Nix P, Hauth L, et al. Axon regeneration 
requires a conserved MAP kinase pathway. Science 2009;323:802-6.

85. Libby RT, Li Y, Savinova OV, et al. Susceptibility to neurodegeneration in a glaucoma is modified by Bax gene dosage. PLoS Genet 2005;1:17-26.

86. Fujiki M, Zhang Z, Guth L, et al. Genetic influences on cellular reactions to spinal cord injury: activation of macrophages/microglia and astrocytes is delayed in mice carrying a mutation (WldS) that causes delayed Wallerian degeneration. J Comp Neurol 1996;371:469-84.

87. Beirowski B, Babetto E, Coleman MP, et al. The WldS gene delays axonal but not somatic degeneration in a rat glaucoma model. Eur J Neurosci 2008;28:1166-79.

88. Williams PA, Harder JM, Foxworth NE, et al. Nicotinamide and WLD. Front Neurosci 2017;11:232.

89. Conforti L, Tarlton A, Mack TG, et al. A Ufd2/D4Cole1e chimeric protein and overexpression of $\mathrm{Rbp} 7$ in the slow Wallerian degeneration (WldS) mouse. Proc Natl Acad Sci U S A 2000;97:11377-82.

90. Mack TG, Reiner M, Beirowski B, et al. Wallerian degeneration of injured axons and synapses is delayed by a Ube4b/Nmnat chimeric gene. Nat Neurosci 2001;4:1199-206.

91. Wang J, Zhai Q, Chen Y, et al. A local mechanism mediates NAD-dependent protection of axon degeneration. J Cell Biol 2005;170:349-55.

92. Gilley J, Coleman MP. Endogenous Nmnat2 is an essential survival factor for maintenance of healthy axons. PLoS Biol 2010;8:e1000300.

93. Gerdts J, Brace EJ, Sasaki Y, et al. SARM1 activation triggers axon degeneration locally via NAD destruction. Science 2015;348:453-7.

94. Osterloh JM, Yang J, Rooney TM, et al. dSarm/Sarm1 is required for activation of an injury-induced axon death pathway. Science 2012;337:481-4.

95. Fernandes KA, Mitchell KL, Patel A, et al. Role of SARM1 and DR6 in retinal ganglion cell axonal and somal degeneration following axonal injury. Exp Eye Res 2018;171:54-61.

96. Summers DW, Milbrandt J, DiAntonio A. Palmitoylation enables MAPK-dependent proteostasis of axon survival factors. Proc Natl Acad Sci U S A 2018;115:E8746-54.

97. Summers DW, Frey E, Walker LJ, et al. DLK Activation Synergizes with Mitochondrial Dysfunction to Downregulate Axon Survival Factors and Promote SARM1-Dependent Axon Degeneration. Mol Neurobiol 2020;57:1146-58

98. Shin JE, Miller BR, Babetto E, et al. SCG10 is a JNK target in the axonal degeneration pathway. Proc Natl Acad Sci U S A 2012;109:E3696-705.

99. Gerdts J, Summers DW, Milbrandt J, et al. Axon SelfDestruction: New Links among SARM1, MAPKs, and NAD+ Metabolism. Neuron 2016;89:449-60.

100.Lunn ER, Perry VH, Brown MC, et al. Absence of Wallerian Degeneration does not Hinder Regeneration in Peripheral Nerve. Eur J Neurosci 1989;1:27-33.

101.Herrera SC, Bach EA. JAK/STAT signaling in stem cells and regeneration: from. Development 2019;146:dev167643.

102. Pernet V, Joly S, Jordi N, et al. Misguidance and modulation of axonal regeneration by Stat 3 and Rho/ ROCK signaling in the transparent optic nerve. Cell Death Dis 2013;4:e734.

103. Müller A, Hauk TG, Fischer D. Astrocyte-derived CNTF switches mature RGCs to a regenerative state following inflammatory stimulation. Brain 2007;130:3308-20.

104. Müller A, Hauk TG, Leibinger M, et al. Exogenous $\mathrm{CNTF}$ stimulates axon regeneration of retinal ganglion cells partially via endogenous CNTF. Mol Cell Neurosci 2009;41:233-46.

105. Fischer D, Pavlidis M, Thanos S. Cataractogenic lens injury prevents traumatic ganglion cell death and promotes axonal regeneration both in vivo and in culture. Invest Ophthalmol Vis Sci 2000;41:3943-54.

106. Smith PD, Sun F, Park KK, et al. SOCS3 deletion promotes optic nerve regeneration in vivo. Neuron 2009;64:617-23.

107. Moore DL, Blackmore MG, Hu Y, et al. KLF family members regulate intrinsic axon regeneration ability. Science 2009;326:298-301.

108. Apara A, Galvao J, Wang Y, et al. KLF9 and JNK3 Interact to Suppress Axon Regeneration in the Adult CNS. J Neurosci 2017;37:9632-44.

109. Darnell JE. STATs and gene regulation. Science 1997;277:1630-5.

110. Schaefer TS, Sanders LK, Nathans D. Cooperative transcriptional activity of Jun and Stat3 beta, a short form of Stat3. Proc Natl Acad Sci U S A 1995;92:9097-101.

111. Shen S, Niso-Santano M, Adjemian S, et al. Cytoplasmic STAT3 represses autophagy by inhibiting PKR activity. Mol Cell 2012;48:667-80.

112.Luo X, Ribeiro M, Bray ER, et al. Enhanced Transcriptional Activity and Mitochondrial Localization of STAT3 Co-induce Axon Regrowth in the Adult Central Nervous System. Cell Rep 2016;15:398-410.

113. Sarbassov DD, Ali SM, Sabatini DM. Growing roles for the 
mTOR pathway. Curr Opin Cell Biol 2005;17:596-603.

114. Homma K, Koriyama Y, Mawatari K, et al. Early downregulation of IGF-I decides the fate of rat retinal ganglion cells after optic nerve injury. Neurochem Int 2007;50:741-8.

115. Sun F, Park KK, Belin S, et al. Sustained axon regeneration induced by co-deletion of PTEN and SOCS3. Nature 2011;480:372-5.

116.Park KK, Liu K, Hu Y, et al. Promoting axon regeneration in the adult CNS by modulation of the PTEN/mTOR pathway. Science 2008;322:963-6.

117.Leibinger M, Andreadaki A, Fischer D. Role of mTOR in neuroprotection and axon regeneration after inflammatory stimulation. Neurobiol Dis 2012;46:314-24.

118. Agostinone J, Alarcon-Martinez L, Gamlin C, et al. Insulin signalling promotes dendrite and synapse regeneration and restores circuit function after axonal injury. Brain 2018;141:1963-80.

119. Ma JJ, Ju X, Xu RJ, et al. Telomerase Reverse Transcriptase and p53 Regulate Mammalian Peripheral Nervous System and CNS Axon Regeneration Downstream of c-Myc. J Neurosci 2019;39:9107-18.

120. Floriddia EM, Rathore KI, Tedeschi A, et al. p53 Regulates the neuronal intrinsic and extrinsic responses affecting the recovery of motor function following spinal cord injury. $\mathrm{J}$ Neurosci 2012;32:13956-70.

121. Yamanaka S, Takahashi K. Induction of pluripotent stem cells from mouse fibroblast cultures. Tanpakushitsu Kakusan Koso 2006;51:2346-51.

122.Lu Y, Brommer B, Tian X, et al. Reprogramming to recover youthful epigenetic information and restore vision. Nature 2020;588:124-9.

123.Ambros V, Horvitz HR. Heterochronic mutants of the nematode Caenorhabditis elegans. Science 1984;226:409-16.

124.Tsialikas J, Romer-Seibert J. LIN28: roles and regulation in development and beyond. Development 2015;142:2397-404.

125.Wang XW, Li Q, Liu CM, et al. Lin28 Signaling Supports Mammalian PNS and CNS Axon Regeneration. Cell Rep 2018;24:2540-52.e6.

126.Zhang Y, Williams PR, Jacobi A, et al. Elevating Growth Factor Responsiveness and Axon Regeneration by Modulating Presynaptic Inputs. Neuron 2019;103:39-51.e5.

127. Belin S, Nawabi H, Wang C, et al. Injury-induced decline of intrinsic regenerative ability revealed by quantitative proteomics. Neuron 2015;86:1000-14.

128. Kurimoto T, Yin Y, Omura K, et al. Long-distance axon regeneration in the mature optic nerve: contributions of oncomodulin, cAMP, and pten gene deletion. J Neurosci 2010;30:15654-63.

129. de Lima S, Habboub G, Benowitz LI. Combinatorial therapy stimulates long-distance regeneration, target reinnervation, and partial recovery of vision after optic nerve injury in mice. Int Rev Neurobiol 2012;106:153-72.

130.Pernet V, Di Polo A. Synergistic action of brain-derived neurotrophic factor and lens injury promotes retinal ganglion cell survival, but leads to optic nerve dystrophy in vivo. Brain 2006;129:1014-26.

131. Masland RH. The neuronal organization of the retina. Neuron 2012;76:266-80.

132.Laboissonniere LA, Goetz JJ, Martin GM, et al. Molecular signatures of retinal ganglion cells revealed through single cell profiling. Sci Rep 2019;9:15778.

133. Rheaume BA, Jereen A, Bolisetty M, et al. Single cell transcriptome profiling of retinal ganglion cells identifies cellular subtypes. Nat Commun 2018;9:2759.

134. Cleland BG, Levick WR, Wässle H. Physiological identification of a morphological class of cat retinal ganglion cells. J Physiol 1975;248:151-71.

135. Famiglietti EV, Kolb H. Structural basis for ON-and OFF-center responses in retinal ganglion cells. Science 1976;194:193-5.

136. KUFFLER SW. Discharge patterns and functional organization of mammalian retina. J Neurophysiol 1953;16:37-68.

137. Martersteck EM, Hirokawa KE, Evarts M, et al. Diverse Central Projection Patterns of Retinal Ganglion Cells. Cell Rep 2017;18:2058-72.

138. Dhande OS, Stafford BK, Lim JA, et al. Contributions of Retinal Ganglion Cells to Subcortical Visual Processing and Behaviors. Annu Rev Vis Sci 2015;1:291-328.

139. Gupta N, Yücel YH. What changes can we expect in the brain of glaucoma patients? Surv Ophthalmol 2007;52 Suppl 2:S122-6.

140. Tran NM, Shekhar K, Whitney IE, et al. Single-Cell Profiles of Retinal Ganglion Cells Differing in Resilience to Injury Reveal Neuroprotective Genes. Neuron 2019;104:1039-55.e12.

141.Duan X, Qiao M, Bei F, et al. Subtype-specific regeneration of retinal ganglion cells following axotomy: effects of osteopontin and mTOR signaling. Neuron 2015;85:1244-56. 
142. Norsworthy MW, Bei F, Kawaguchi R, et al. Sox11 Expression Promotes Regeneration of Some Retinal Ganglion Cell Types but Kills Others. Neuron 2017;94:1112-20.e4.

143.Lim JH, Stafford BK, Nguyen PL, et al. Neural activity promotes long-distance, target-specific regeneration of adult retinal axons. Nat Neurosci 2016;19:1073-84.

144.Peng YR, Shekhar K, Yan W, et al. Molecular Classification and Comparative Taxonomics of Foveal and Peripheral Cells in Primate Retina. Cell 2019;176:1222-37.e22.

145. Sanes JR, Masland RH. The types of retinal ganglion cells: current status and implications for neuronal classification. Annu Rev Neurosci 2015;38:221-46.

146.Kaplan E. The M, P, and K pathways of the primate visual system. In: Chalupa LM, Werner JS, editors. The Visual Neurosciences. Cambridge, MA: MIT Press; 2004. p. 481-93.

147.Li Y, Andereggen L, Yuki K, et al. Mobile zinc increases rapidly in the retina after optic nerve injury and regulates ganglion cell survival and optic nerve regeneration. Proc Natl Acad Sci U S A 2017;114:E209-18.

148. Casson RJ. Possible role of excitotoxicity in the pathogenesis of glaucoma. Clin Exp Ophthalmol 2006;34:54-63.

149. Itoh N, Nagata S. A novel protein domain required for apoptosis. Mutational analysis of human Fas antigen. J Biol Chem 1993;268:10932-7.

150. Nakazawa T, Nakazawa C, Matsubara A, et al. Tumor necrosis factor-alpha mediates oligodendrocyte death and delayed retinal ganglion cell loss in a mouse model of glaucoma. J Neurosci 2006;26:12633-41.

151. Sawada H, Fukuchi T, Tanaka T, et al. Tumor necrosis factor-alpha concentrations in the aqueous humor of patients with glaucoma. Invest Ophthalmol Vis Sci 2010;51:903-6.

152. Cueva Vargas JL, Osswald IK, Unsain N, et al. Soluble Tumor Necrosis Factor Alpha Promotes Retinal Ganglion Cell Death in Glaucoma via Calcium-Permeable AMPA Receptor Activation. J Neurosci 2015;35:12088-102.

153.Ebadi M, Bashir RM, Heidrick ML, et al. Neurotrophins and their receptors in nerve injury and repair. Neurochem Int 1997;30:347-74.

154. Mey J, Thanos S. Intravitreal injections of neurotrophic factors support the survival of axotomized retinal ganglion cells in adult rats in vivo. Brain Res 1993;602:304-17.

155. Di Polo A, Aigner LJ, Dunn RJ, et al. Prolonged delivery of brain-derived neurotrophic factor by adenovirus- infected Müller cells temporarily rescues injured retinal ganglion cells. Proc Natl Acad Sci U S A 1998;95:3978-83.

156.Pease ME, McKinnon SJ, Quigley HA, et al. Obstructed axonal transport of BDNF and its receptor TrkB in experimental glaucoma. Invest Ophthalmol Vis Sci 2000;41:764-74.

157. Quigley HA, McKinnon SJ, Zack DJ, et al. Retrograde axonal transport of BDNF in retinal ganglion cells is blocked by acute IOP elevation in rats. Invest Ophthalmol Vis Sci 2000;41:3460-6.

158. Leibinger M, Müller A, Andreadaki A, et al.

Neuroprotective and axon growth-promoting effects following inflammatory stimulation on mature retinal ganglion cells in mice depend on ciliary neurotrophic factor and leukemia inhibitory factor. J Neurosci 2009;29:14334-41.

159. Chen ZL, Yu WM, Strickland S. Peripheral regeneration. Annu Rev Neurosci 2007;30:209-33.

160.Jessen KR, Mirsky R, Lloyd AC. Schwann Cells: Development and Role in Nerve Repair. Cold Spring Harb Perspect Biol 2015;7:a020487.

161. Ramon y Cajal S. Degeneration and Regeneration of the Nervous System. New York: Oxford University Press; 1991.

162.Bray GM, Villegas-Pérez MP, Vidal-Sanz M, et al. The use of peripheral nerve grafts to enhance neuronal survival, promote growth and permit terminal reconnections in the central nervous system of adult rats. J Exp Biol 1987;132:5-19.

163. Vidal-Sanz M, Bray GM, Villegas-Pérez MP, et al. Axonal regeneration and synapse formation in the superior colliculus by retinal ganglion cells in the adult rat. J Neurosci 1987;7:2894-909.

164.Vidal-Sanz M, Bray GM, Aguayo AJ. Regenerated synapses persist in the superior colliculus after the regrowth of retinal ganglion cell axons. J Neurocytol 1991;20:940-52.

165.Schwab ME, Thoenen H. Dissociated neurons regenerate into sciatic but not optic nerve explants in culture irrespective of neurotrophic factors. J Neurosci 1985;5:2415-23.

166.Schnell L, Schwab ME. Axonal regeneration in the rat spinal cord produced by an antibody against myelin-associated neurite growth inhibitors. Nature 1990;343:269-72.

167.McKerracher L, David S, Jackson DL, et al. Identification of myelin-associated glycoprotein as a major myelin-derived inhibitor of neurite growth. Neuron 1994;13:805-11. 
168. Chen MS, Huber AB, van der Haar ME, et al. Nogo-A is a myelin-associated neurite outgrowth inhibitor and an antigen for monoclonal antibody IN-1. Nature 2000;403:434-9.

169. Wang KC, Koprivica V, Kim JA, et al. Oligodendrocytemyelin glycoprotein is a Nogo receptor ligand that inhibits neurite outgrowth. Nature 2002;417:941-4.

170.Domeniconi M, Cao Z, Spencer T, et al. Myelin-associated glycoprotein interacts with the Nogo66 receptor to inhibit neurite outgrowth. Neuron 2002;35:283-90.

171. Kottis V, Thibault P, Mikol D, et al. Oligodendrocytemyelin glycoprotein (OMgp) is an inhibitor of neurite outgrowth. J Neurochem 2002;82:1566-9.

172. Fischer D, He Z, Benowitz LI. Counteracting the Nogo receptor enhances optic nerve regeneration if retinal ganglion cells are in an active growth state. J Neurosci 2004;24:1646-51.

173. Dickendesher TL, Baldwin KT, Mironova YA, et al. $\mathrm{NgR} 1$ and NgR3 are receptors for chondroitin sulfate proteoglycans. Nat Neurosci 2012;15:703-12.

174. Kucher K, Johns D, Maier D, et al. First-in-Man Intrathecal Application of Neurite Growth-Promoting Anti-Nogo-A Antibodies in Acute Spinal Cord Injury. Neurorehabil Neural Repair 2018;32:578-89.

175.McKeon RJ, Schreiber RC, Rudge JS, et al. Reduction of neurite outgrowth in a model of glial scarring following CNS injury is correlated with the expression of inhibitory molecules on reactive astrocytes. J Neurosci 1991;11:3398-411.

176. Fitch MT, Doller C, Combs CK, et al. Cellular and molecular mechanisms of glial scarring and progressive cavitation: in vivo and in vitro analysis of inflammationinduced secondary injury after CNS trauma. J Neurosci 1999; 19:8182-98.

177. Fabes J, Anderson P, Yáñez-Muñoz RJ, et al. Accumulation of the inhibitory receptor EphA4 may prevent regeneration of corticospinal tract axons following lesion. Eur J Neurosci 2006;23:1721-30.

178. Bradbury EJ, Moon LD, Popat RJ, et al. Chondroitinase $\mathrm{ABC}$ promotes functional recovery after spinal cord injury. Nature 2002;416:636-40.

179.Anderson MA, Burda JE, Ren Y, et al. Astrocyte scar formation aids central nervous system axon regeneration. Nature 2016;532:195-200.

180. Mimura F, Yamagishi S, Arimura N, et al. Myelinassociated glycoprotein inhibits microtubule assembly by a Rho-kinase-dependent mechanism. J Biol Chem 2006;281:15970-9.
181.Harboe M, Torvund-Jensen J, Kjaer-Sorensen K, et al. Ephrin-A1-EphA4 signaling negatively regulates myelination in the central nervous system. Glia 2018;66:934-50.

182.Lehmann M, Fournier A, Selles-Navarro I, et al. Inactivation of Rho signaling pathway promotes CNS axon regeneration. J Neurosci 1999;19:7537-47.

183. Fischer D, Petkova V, Thanos S, et al. Switching mature retinal ganglion cells to a robust growth state in vivo: gene expression and synergy with RhoA inactivation. J Neurosci 2004;24:8726-40.

184. Ellis RE, Jacobson DM, Horvitz HR. Genes required for the engulfment of cell corpses during programmed cell death in Caenorhabditis elegans. Genetics 1991;129:79-94.

185.Zhou Z, Hartwieg E, Horvitz HR. CED-1 is a transmembrane receptor that mediates cell corpse engulfment in C. elegans. Cell 2001;104:43-56.

186. Suzuki E, Nakayama M. MEGF10 is a mammalian ortholog of CED-1 that interacts with clathrin assembly protein complex 2 medium chain and induces large vacuole formation. Exp Cell Res 2007;313:3729-42.

187. Hanayama R, Tanaka M, Miwa K, et al. Identification of a factor that links apoptotic cells to phagocytes. Nature 2002;417:182-7.

188. Fadok VA, Voelker DR, Campbell PA, et al. Exposure of phosphatidylserine on the surface of apoptotic lymphocytes triggers specific recognition and removal by macrophages. J Immunol 1992;148:2207-16.

189. Cordeiro MF, Normando EM, Cardoso MJ, et al. Realtime imaging of single neuronal cell apoptosis in patients with glaucoma. Brain 2017;140:1757-67.

190.Schmitz-Valckenberg S, Guo L, Maass A, et al. Realtime in vivo imaging of retinal cell apoptosis after laser exposure. Invest Ophthalmol Vis Sci 2008;49:2773-80.

191. Kreutzberg GW. Microglia: a sensor for pathological events in the CNS. Trends Neurosci 1996;19:312-8.

192. Yuan TF, Liang YX, Peng B, et al. Local proliferation is the main source of rod microglia after optic nerve transection. Sci Rep 2015;5:10788.

193.Paolicelli RC, Bolasco G, Pagani F, et al. Synaptic pruning by microglia is necessary for normal brain development. Science 2011;333:1456-8.

194. Rice RA, Spangenberg EE, Yamate-Morgan H, et al. Elimination of Microglia Improves Functional Outcomes Following Extensive Neuronal Loss in the Hippocampus. J Neurosci 2015;35:9977-89.

195.Fan R, Xu F, Previti ML, et al. Minocycline reduces microglial activation and improves behavioral deficits in 
a transgenic model of cerebral microvascular amyloid. J Neurosci 2007;27:3057-63.

196. Bosco A, Inman DM, Steele MR, et al. Reduced retina microglial activation and improved optic nerve integrity with minocycline treatment in the DBA/2 J mouse model of glaucoma. Invest Ophthalmol Vis Sci 2008;49:1437-46.

197.Hilla AM, Diekmann H, Fischer D. Microglia Are Irrelevant for Neuronal Degeneration and Axon Regeneration after Acute Injury. J Neurosci 2017;37:6113-24.

198. Hellsten U, Harland RM, Gilchrist MJ, et al. The genome of the Western clawed frog Xenopus tropicalis. Science 2010;328:633-6.

199. Howe K, Clark MD, Torroja CF, et al. The zebrafish reference genome sequence and its relationship to the human genome. Nature 2013;496:498-503.

200. Sperry R. Optic nerve regeneration with return of vision in anurans. American Physiological Society; 1944.

201. GAZE RM. Regeneration of the optic nerve in Xenopus laevis. Q J Exp Physiol Cogn Med Sci 1959;44:290-308.

202. Meyer RL, Sakurai K, Schauwecker E. Topography of regenerating optic fibers in goldfish traced with local wheat germ injections into retina: evidence for discontinuous microtopography in the retinotectal projection. J Comp Neurol 1985;239:27-43.

203. Straznicky K, Gaze RM. The growth of the retina in Xenopus laevis: an autoradiographic study. J Embryol Exp Morphol 1971;26:67-79.

204.Johns PR. Growth of the adult goldfish eye. III. Source of the new retinal cells. J Comp Neurol 1977;176:343-57.

205. Fausett BV, Goldman D. A role for alpha1 tubulinexpressing Müller glia in regeneration of the injured zebrafish retina. J Neurosci 2006;26:6303-13.

206. Ramachandran R, Fausett BV, Goldman D. Ascl1a regulates Müller glia dedifferentiation and retinal regeneration through a Lin-28-dependent, let7 microRNA signalling pathway. Nat Cell Biol 2010;12:1101-7.

207.Zhao XF, Wan J, Powell C, et al. Leptin and IL-6 family cytokines synergize to stimulate Müller glia reprogramming and retina regeneration. Cell Rep 2014;9:272-84.

208. Bosco L. Transdifferentiation of ocular tissues in larval Xenopus laevis. Differentiation 1988;39:4-15.

209. Yoshii C, Ueda Y, Okamoto M, et al. Neural retinal regeneration in the anuran amphibian Xenopus laevis postmetamorphosis: transdifferentiation of retinal pigmented epithelium regenerates the neural retina. Dev Biol
2007;303:45-56.

210.Zou S, Tian C, Ge S, et al. Neurogenesis of retinal ganglion cells is not essential to visual functional recovery after optic nerve injury in adult zebrafish. PLoS One 2013;8:e57280.

211.Liu Y, Yu H, Deaton SK, et al. Heterogeneous nuclear ribonucleoprotein $\mathrm{K}$, an RNA-binding protein, is required for optic axon regeneration in Xenopus laevis. J Neurosci 2012;32:3563-74.

212.Diekmann H, Kalbhen P, Fischer D. Characterization of optic nerve regeneration using transgenic zebrafish. Front Cell Neurosci 2015;9:118.

213. Matsukawa T, Arai K, Koriyama Y, et al. Axonal regeneration of fish optic nerve after injury. Biol Pharm Bull 2004;27:445-51.

214.Zhao Y, Szaro BG. The return of phosphorylated and nonphosphorylated epitopes of neurofilament proteins to the regenerating optic nerve of Xenopus laevis. J Comp Neurol 1994;343:158-72.

215. Whitworth GB, Misaghi BC, Rosenthal DM, et al. Translational profiling of retinal ganglion cell optic nerve regeneration in Xenopus laevis. Dev Biol 2017;426:360-73.

216. Beaver RS, Dunlop SA, Harman AM, et al. Continued neurogenesis is not a pre-requisite for regeneration of a topographic retino-tectal projection. Vision Res 2001;41:1765-70.

217. Bohn RC, Reier PJ. Retrograde degeneration of myelinated axons and re-organization in the optic nerves of adult frogs (Xenopus laevis) following nerve injury or tectal ablation. J Neurocytol 1985;14:221-44.

218. SPERRY RW. The problem of central nervous reorganization after nerve regeneration and muscle transposition. Q Rev Biol 1945;20:311-69.

219. Meyer RL. Mapping the normal and regenerating retinotectal projection of goldfish with autoradiographic methods. J Comp Neurol 1980;189:273-89.

220.Adamson J, Burke J, Grobstein P. Recovery of the ipsilateral oculotectal projection following nerve crush in the frog: evidence that retinal afferents make synapses at abnormal tectal locations. J Neurosci 1984;4:2635-49.

221. Meyer RL. Tetrodotoxin inhibits the formation of refined retinotopography in goldfish. Brain Res 1983;282:293-8.

222. Schmidt JT, Edwards DL. Activity sharpens the map during the regeneration of the retinotectal projection in goldfish. Brain Res 1983;269:29-39.

223. Bastmeyer M, Beckmann M, Schwab ME, et al. Growth of regenerating goldfish axons is inhibited by rat 
oligodendrocytes and CNS myelin but not but not by goldfish optic nerve tract oligodendrocytelike cells and fish CNS myelin. J Neurosci 1991;11:626-40.

224. Veldman MB, Bemben MA, Thompson RC, et al. Gene expression analysis of zebrafish retinal ganglion cells during optic nerve regeneration identifies KLF6a and KLF7a as important regulators of axon regeneration. Dev Biol 2007;312:596-612.

225. Matsukawa T, Morita K, Omizu S, et al. Mechanisms of RhoA inactivation and CDC42 and Rac1 activation during zebrafish optic nerve regeneration. Neurochem Int
2018;112:71-80.

226. Dhara SP, Rau A, Flister MJ, et al. Cellular reprogramming for successful CNS axon regeneration is driven by a temporally changing cast of transcription factors. Sci Rep 2019;9:14198.

227.Szaro BG, Loh YP. Changes in axonal transport and glial proteins during optic nerve regeneration in Xenopus laevis. Curr Top Dev Biol 1987;21:217-54.

228. Lewis C. The Abolition of Man. London: Oxford University Press; 1943.

Cite this article as: Fague L, Liu YA, Marsh-Armstrong N. The basic science of optic nerve regeneration. Ann Transl Med 2021;9(15):1276. doi: 10.21037/atm-20-5351 